\title{
The search for preserved late-stage accretionary components in terrestrial materials
}

KATHERINE R. BERMINGHAM ${ }^{1}$, RICHARD J. WALKER $^{2}$, VALERIE A. FINLAYSON ${ }^{2}$, HOPE A. TORNABENE ${ }^{2}$, BRADLEY PETERS ${ }^{3}$, JAMES M. D. DAY ${ }^{4}$, ROBERTA L. RUDNICK ${ }^{5}$, NAO NAKANISHI ${ }^{2}$, MATTHEW G. JACKSON ${ }^{6}$, D. GRAHAM PEARSON ${ }^{7}$ AND MANUEL E. SCHILLING $^{8}$

${ }^{1}$ Rutgers University

${ }^{2}$ University of Maryland

${ }^{3}$ Institut für Geochemie und Petrologie, ETH, Switzerland

${ }^{4}$ Scripps Institution of Oceanography

${ }^{5}$ University of California at Santa Barbara

${ }^{6}$ University of California, Santa Barbara

${ }^{7}$ University of Alberta

${ }^{8}$ Universidad Austral de Chile

Presenting Author: katherine.bermingham@rutgers.edu

Comparison of mass-independent isotope compositions of meteorites and terrestrial samples may allow identification of Earth's building blocks. Meteorites inherit mass-independent nucleosynthetic isotope variations from the heterogeneous distribution of presolar materials in the protosolar disk. These cosmic isotope variations delineate typically 'wet' carbonaceous chondrite meteorites from 'dry' non-carbonaceous chondrite meteorites [1]. Siderophile element isotope compositions (e.g., $\mathrm{Mo}, \mathrm{Ru}$ ) have the utility of potentially tracing the timing of volatile delivery to Earth as the Mo and Ru terrestrial mantle budgets ostensibly record the addition of the last 10-20 wt. \% and $\sim 0.5$ wt. $\%$ of mass to Earth, respectively [2]. The proposition that nucleosynthetic isotope signatures may be present in the accessible mantle is supported by preserved primordial mantle domains identified using the radiogenic ${ }^{182} \mathrm{Hf}_{-}{ }^{182} \mathrm{~W}$ system, which recorded differentiation events during the first $\sim 60$ Myr of Earth history [3]. Recently, [4] reported a Ru isotope signature in $\sim 3.7 \mathrm{Ga}$ rocks from southwest Greenland that the authors interpreted as reflecting preservation of a nucleosynthetic signature of pre-late accreted material. Similar isotope variations are anticipated for Mo. We are extending the search for nucleosynthetic isotope anomalies in the mantle by determining the Mo isotope composition of ocean island basalts, granites, diamictites, kimberlites, mid-ocean ridge basalts, and molybdenites. Combined with ${ }^{182} \mathrm{~W}$ isotope compositions, we assess if and how primordial mantle domains were formed and preserved.

[1] Warren, P. H. (2011) Earth Planet. Sci. Lett. 311, 93.

[2] Dauphas, N. (2017) Nature 541, 521.

[3] Touboul et al., (2012) Science 335, 1065.

[4] Fischer-Gödde M. et al., (2020) Nature, 579, 240. 